\title{
UM OLHAR SOBRE A VIOLAÇÃO DOS DIREITOS HUMANOS NA CONSTRUÇÃO DA USINA HIDRELÉTRICA SÃO ROQUE
}

\author{
Antônio Valmor de Campos* \\ Carmen Rejane Flores Wizniewsky" \\ Jane Acordi de Campos
}

\begin{abstract}
Resumo
O presente estudo trata da violação dos direitos humanos na construção da Usina Hidrelétrica (UHE) São Roque, em construção no rio Canoas, entre os municípios de Vargem e São José do Cerrito em Santa Catarina. O embasamento empírico decorre de diálogos individuais, encontros, mobilizações e documentos produzidos pelos próprios atingidos. $\mathrm{O}$ embasamento teórico é respaldado em diversos documentos de comissões de direitos humanos que analisaram as violações de direitos humanos em outras obras, além dos tratados e acordos internacionais dos quais o Brasil é signatário e os incorporou em sua legislação. Também são demonstrados os principais direitos negados aos atingidos e como se concretiza a violação de direitos humanos nesse caso. Ainda é realizada uma discussão sobre o papel do Movimento dos Atingidos por Barragens (MAB) na luta em defesa dos direitos dos atingidos e sua legitimidade de representação. Também se propõe uma sugestão de conceituação de atingido e dos mecanismos necessários para a garantia de seus direitos. Por fim, indica um conjunto de procedimentos que deveria ser tomado para cessar as violações de direitos humanos na finalização da obra e em seu funcionamento.
\end{abstract}

Palavras-chave: Direitos Humanos. Movimento Social. Setor Energético. Barragem.

\footnotetext{
* Doutorando pela Universidade Federal de Santa Maria (UFSM), no Programa de Pós-Graduação em Geografia (PPGEO), docente da Universidade Federal da Fronteira Sul (UFFS) - Campi Chapecó.

E-mail: antonio.campos@uffs.edu.br

** Doutora em Geografia, com revalidação de Título no Exterior pela Universidade Federal de Santa Catarina (UFSC) - doutorado em Geografia e Ciências do Território, pela Universidad de Córdoba, na Espanha; docente junto ao Programa de Pós-Graduação em Geografia (PPGEO) na Universidade Federal de Santa Maria (UFSM).E-mail: carmenrejanefw@gmail.com

*** Mestranda no Programa de Pós-Graduação Stricto Sensu em Educação na Universidade Comunitária da Região de Chapecó (Unochapecó), professora da Rede Pública Oficial de Ensino de Santa Catarina.

E-mail: janecampos@unochapeco.edu.br.
} 


\section{Introdução}

O presente artigo tem a intenção de demonstrar o quanto a política energética no Brasil é perversa para um segmento social desprotegido (os atingidos). O olhar no presente caso está voltado para uma situação concreta - em andamento - no estado de Santa Catarina, região serrana, atingindo diversos municípios, mas principalmente Vargem e São José do Cerrito com o empreendimento da Usina Hidrelétrica (UHE) São Roque em construção no Rio Canoas.

A violação de direitos humanos em situações como essa tem inúmeros registros, em moldes semelhantes. A intenção é trazer presente essas violações, permitindo a necessária reflexão acerca do problema - especialmente quando se referem a considerações indispensáveis sobre a ação do capital nessas obras, com reflexos sobre a cultura, as tradições, o modo de vida e o patrimônio material e imaterial construído pelos atingidos, pelas gerações passadas e pela atual.

A descrição decorre do acompanhamento das atividades que têm por objetivo discutir a situação dos atingidos e as violações dos seus direitos, feitas pelos autores, no desempenho de atividades profissionais ou do ativismo nos direitos humanos. Portanto, será possível visualizar o cenário de várias atividades desencadeadas pelo Movimento de Atingidos por Barragens (MAB) nessa luta.

Observa-se que, no desenrolar dos acontecimentos, foram parcos os avanços nas negociações e na garantia dos direitos dos atingidos, o que ficará demonstrado no decorrer do texto. Apresenta-se, inicialmente, uma caracterização da situação vivida pelos atingidos da UHE São Roque, na intenção de situar o leitor acerca da localização espacial e temporal dos acontecimentos. Além disso, procura-se demonstrar o território, na compreensão de que espaço e território "[...] não são termos equivalentes [...]. É essencial compreender bem que o espaço é anterior ao território. O território se forma a partir do espaço, é resultado de uma ação conduzida por um ator sintagmático (ator que realiza 
um programa) em qualquer nível" (RAFFESTIN, 1993, p. 143). E também: "O território é um destes conceitos complexos, substantivado por vários elementos, no nível do pensamento e em unidade com o mundo da vida" (SAQUET, 2015, p. 13). Portanto, ocorre um processo de desterritorialização dos atingidos - nos aspectos econômicos, sociais, políticos e culturais da população - para dar lugar à exploração daquele espaço pelo capital, descaracterizando o ambiente, o próprio espaço e o território.

Em seguida, apresenta-se um pequeno demonstrativo de como os direitos humanos são violados, estabelecendo interfaces com os históricos de outras obras. Apresenta-se um aporte jurídico fundamentado na Constituição Federal, em tratados e acordos internacionais, no próprio contrato de concessão, além de produções diversas sobre a violação de direitos humanos em obras como essa.

Outra questão tratada diz respeito ao conceito de atingido, tendo em vista que, pelas análises existentes, esse é o ponto central de geração de violência e da violação de direitos humanos nas obras de construção de barragens. Por fim, apresentam-se algumas contribuições acerca da necessidade de aprofundamento dos debates com o objetivo de estancar a violação dos direitos humanos no caso em estudo, bem como prevenir as violações em futuras concessões. Espera-se, ao menos, que o presente tenha um significado para os ativistas nas lutas em defesa dos direitos dos atingidos, os quais não lutam por interesses pessoais ou corporativos, mas pela utopia de garantir a "humanidade para os humanos" que estão fora dela e sofrem a ameaça de ficar ainda mais à margem dos benefícios do desenvolvimento produzido à custa de sua desestruturação familiar, social, política, econômica e cultural.

\section{Do contexto da execução da obra}

A concessão de construção e exploração da UHE São Roque tem seu início efetivo - apesar de o estudo inicial ser do ano de 2002 - a partir do ano de 2012, com a assinatura 
do contrato entre o Ministério de Minas e Energia e o empreendedor, como se verifica: "[...] denominada neste contrato com UHE, cuja concessão foi autorizada por meio do Decreto de $1^{\circ}$ de agosto de 2012, publicado no Diário Oficial [da União] no 149, de 2 de agosto de 2012" (BRASIL, 2012, [s. p.]).

A referida concessão tem prazo de 35 anos, como consta no referido contrato: "O contrato de concessão tem prazo de trinta e cinco anos, contados a partir da data de sua assinatura, sem previsão de prorrogação na legislação vigente" (BRASIL, 2012, [s. p.]). Nesse contrato, quase nada de referência é feito às pessoas que habitam o local atingido e seu entorno - principalmente acerca de garantia de seus direitos -, apenas na cláusula sétima, subcláusula primeira, está presente um indicativo:

XVII - Apresentar o Cadastro Socioeconômico da População Atingida, pela UHE observando o disposto no Decreto no 7.342, de 26 de outubro de 2010, e sua regulamentação a ser estabelecida em conjunto dos Ministérios de Minas e Energia, do Meio Ambiente, da Agricultura, Pecuária e Abastecimento, do Desenvolvimento Agrário e da Pesca e Aquicultura. (BRASIL, 2012, [s. p.]).

Apesar de o Brasil não possuir uma lei que estabeleça efetivamente os direitos dos atingidos, há um Decreto que sinaliza algumas condicionantes, as quais poderiam amenizar os efeitos das barragens, como o artigo segundo, in verbis:

Art. 2을 $\mathrm{O}$ cadastro socioeconômico previsto no art. $1^{\text {o }}$ deverá contemplar os integrantes de populações sujeitos aos seguintes impactos:

I - perda de propriedade ou da posse de imóvel localizado no polígono do empreendimento;

II - perda da capacidade produtiva das terras de parcela remanescente de imóvel que faça limite com o polígono do empreendimento e por ele tenha sido parcialmente atingido;

III - perda de áreas de exercício da atividade pesqueira e dos recursos pesqueiros, inviabilizando a atividade extrativa ou produtiva; 
IV - perda de fontes de renda e trabalho das quais os atingidos dependam economicamente, em virtude da ruptura de vínculo com áreas do polígono do empreendimento;

$\mathrm{V}$ - prejuízos comprovados às atividades produtivas locais, com inviabilização de estabelecimento;

VI - inviabilização do acesso ou de atividade de manejo dos recursos naturais e pesqueiros localizados nas áreas do polígono do empreendimento, incluindo as terras de domínio público e uso coletivo, afetando a renda, a subsistência e o modo de vida de populações; e VII - prejuízos comprovados às atividades produtivas locais a jusante e a montante do reservatório, afetando a renda, a subsistência e o modo de vida de populações. (BRASIL, 2010b).

Ocorre que, pelos relatos dos atingidos, bem como da observação da situação fática, sequer o presente decreto está sendo observado. No entanto, na visão da empresa e da imprensa em geral - ressalvadas as exceções -, a Usina Hidrelétrica São Roque é um empreendimento de proporção grandiosa para a região, que exigirá investimentos milionários; portanto, seriam justificadas as violações de direitos.

A UHE São Roque está sendo construída entre os municípios de Vargem e São José do Cerrito, com aproveitamento hidrelétrico projetado para o rio Canoas, com área atingida pelo reservatório de 4.577 hectares atingindo comunidades de cinco municípios catarinenses Brunópolis, Curitibanos, Vargem, São José do Cerrito e Frei Rogério.

Segundo os empreendedores, a construção da UHE São Roque é um empreendimento que estava projetado há anos, e o qual já gerava muita especulação dentre a população, quando estava ainda em fase de liberação da Licença Ambiental Prévia (LAP). Essa expectativa decorre do entendimento popular de que em situações como essa, ocorreria uma justa compensação pelos transtornos e desagregações familiares e comunitárias causados pela obra. Além disso, havia uma compreensão que esse seria o direito garantido por lei. No entanto, isso não se confirmou e tem provocado inquietações entre os atingidos. 
No momento, mesmo com a paralisação da obra, quando comparado ao ritmo desta, com o deslocamento e colocação dos atingidos, muito pouco ainda foi efetivado pela empresa para amenizar a questão da compensação social, bem como para garantir a justa indenização ou a recolocação dos atingidos.Pelas análises preliminares, percebe-se que a empresa está se aproveitando da desinformação das pessoas atingidas para ludibriá-los. Como os ribeirinhos atingidos são pessoas de bem, de boa-fé, acabam sendo submetidos à exploração em diversas ordens. Por exemplo, há relatos de pagamentos feitos em atraso, de pessoas desalojadas judicialmente sem a efetiva necessidade, além do descumprimento de prazos e requisitos legalmente estabelecidos no contrato de concessão.

Observando alguns dados documentais e relatos, percebe-se que 1,3 mil pessoas vivem na área a ser alagada, havendo necessidade de eliminação de aproximadamente 345 casas da área rural, além de igrejas, cemitérios, escolas, estradas e pontes. Isso tudo somente na área alagada, e existe, posteriormente, o problema da faixa de preservação ambiental, na qual ocorre restrição de uso. Importa mencionar que os empreendedores, sistematicamente, têm se negado a indenizar essas áreas e o poder público é inerte.

A violação dos direitos humanos - como ocorre em todas as obras semelhantes - se desenha em diversos níveis, seja no aspecto social, cultural ou financeiro. No entanto, pelos relatos do MAB, nessa obra ocorre um agravamento das violações, talvez pelas próprias características da população atingida, porque esta tem baixa escolaridade e poucas condições de uma efetiva organização capaz de fazer frente ao problema instalado.

Para a referida obra, são apresentados dados de investimentos, com financiamento do Banco Nacional de Desenvolvimento Social (BNDES); porém, nada se cogita de valores para aqueles que são vítimas do projeto, os atingidos. Portanto, isso, por si, já representa uma grave violação de 
seus direitos, os quais normalmente não se preocupam com o valor material das terras, seja as do arrendamento, parceria ou próprias, pois o importante é produzir, ao menos para sua família e comercialização do excedente.

Com o início da execução da obra, nada mais tem o mesmo valor, tendo em vista que os atingidos são impedidos de fazer melhorias, são forçados a abandonar suas terras e, muitas vezes, o valor da indenização não garante uma nova colocação; afinal, normalmente as terras ribeirinhas não têm a mesma valorização, comparadas com as demais áreas agricultáveis da região.

Outra situação presente na região de abrangência das obras é a das famílias que têm seu direito negado, haja vista o não atendimento dos critérios estabelecidos pela empresa para o enquadramento na indenização. $\mathrm{O}$ fato de ser uma obra considerada de "interesse social", pela importância que teria ao desenvolvimento regional e local, acaba monopolizando o poder, sobrepondo-se aos costumes, às tradições e à cultura dos ribeirinhos atingidos.

A tensão no local tomou proporções costumeiras nessas relações. Evidentemente que ainda não é possível dimensionar a correta configuração e a proporção das violações de direitos, considerando que muitas pessoas sequer têm a dimensão que estão sendo vítimas. Portanto, o desafio para as organizações de direitos humanos é ainda maior, pois será preciso discutir os próprios direitos, para tornar possível dimensionar a presença das violações e a gravidade dessas.

Em tentativa de identificação da dimensão do problema, o MAB, juntamente com a Igreja Católica da Região - com participação direta do bispo da diocese de Lages -, com o Ministério Público Federal, com a Universidade Federal da Fronteira Sul (UFFS), sindicatos da região e de outras instituições têm realizado seminários e encontros na região. Um desses encontros aconteceu no dia 20 de março de 2015, no município de Vargem/SC, participaram mais de 200 atingidos. Nesse evento, foi feita uma ampla discussão acerca da situação dos atingidos frente ao ritmo acelerado das obras, 
sem a contrapartida e a preocupação com o problema social que está se processando com a construção da barragem. Estiveram presentes lideranças comunitárias, políticas e religiosas, as quais tomaram posição acerca das violações de direitos recorrentes no território da obra. Naquele momento constatou-se, a partir das diversas intervenções, que a população local vive em situação de grande abandono, seja pela empresa, seja pelas autoridades administrativas. Pouco se visualiza em ações do Ministério Público ou do Judiciário - especialmente estadual - em defesa dos atingidos; ao contrário, as intervenções normalmente são na defesa dos interesses do empreendimento, em que são analisados apenas os aspectos estritamente legais, deixando de considerar os elementos constantes dos direitos humanos, que possuem maior amplitude.

As violações ocorrem, inclusive, nas negociações já efetivadas, nas quais os atingidos não receberam os valores corretamente. Também o próprio valor ofertado pela empresa é motivo de descontentamento geral entre os atingidos, pois na maior parte das avaliações não é possível adquirir outra propriedade em condições adequadas, ao menos semelhantes as que possuem.

De acordo com os atingidos, há falta de valorização das benfeitorias e das terras, tendo em conta que boa parte delas não é reconhecida e valorizada pela empresa, repercutindo negativamente nos valores calculados para a indenização. Pelas informações colhidas, nessa situação, encontra-se grande parte dos atingidos pela barragem da usina São Roque. Inclusive isso já foi registrado em audiência no Ministério Público Federal de Joaçaba, da qual se extrai o seguinte:

A comunidade também questionou que os levantamentos para a apuração de valores médios de indenização foram efetuados em áreas muito diferentes daquelas que são atingidas, sendo que foram comparadas com os locais que não tem utilização agrícola, o que não é a realidade dos locais atingidos, onde as áreas são produtivas. (MPF, 2010, [s. p.]). 
Estão presentes outras situações ainda mais graves. Há grande quantidade de famílias excluídas do levantamento socioeconômico de forma arbitrária, pela empresa, de acordo com as informações apresentadas pelos atingidos presentes são quase a metade do número inicial que ficaram excluídos. Essa condição também já se encontra registrada nos autos de Inquérito Civil do Ministério Público Federal (MPF) - Joaçaba: "Que há muitos casos de filhos de agricultores que residem nas áreas atingidas que não têm título, que não constam em nenhum cadastro, sendo que o empreendedor não manifestou qual a solução" (MPF, 2010, [s. p.]).

Aparentemente, algumas autoridades locais e regionais - comunitárias, sindicais, políticas e religiosas - têm se manifestado em favor dos atingidos, na intenção de buscar alternativas para minimizar os impactos da construção da barragem, com destaque ao Ministério Público Federal, na pessoa do procurador Mário Roberto dos Santos. No entanto, as intervenções do MPF encontram limitações nos termos legais e a garantia dos direitos humanos. E, em casos como esses, carece de ir além da legislação, observando, por exemplo, a dignidade da pessoa humana. Isso é possível considerando os tratados internacionais e outros instrumentos, os quais nem sempre são recepcionados plenamente pelo Judiciário brasileiro, especialmente nas comarcas estaduais, que de uma forma ou outra acabam influenciados por diversos aspectos locais e regionais, há sempre a tendência de as decisões judiciais não contemplarem os anseios dos atingidos.

As violações presentes na construção da UHE São Roque não são novidades para o movimento de atingidos, pois inúmeras outras experiências semelhantes, inclusive na própria região Sul já passaram pelos mesmos flagelos de violações. Segundo o manual do atingido, houve um "planejamento estratégico" de o governo militar para transformar a região em um local de grande potencial energético, como está explícito no manual, segundo a Associação Coordenação Nacional dos Atingidos por Barragens (ANAB): "Na Região Sul, na Bacia do Rio Uruguai, o Plano 2010 da Eletrobrás projetava a 
construção de 23 barragens, que expulsariam 200.000 pessoas nos estados do Rio Grande do Sul e Santa Catarina” (2013, [s.p.]).

Com a experiência acumulada pelos dirigentes do MAB, em diversas outras lutas semelhantes, é possível oferecer subsídios aos atingidos para enfrentar com maior ênfase as violações patrocinadas pelos investidores do setor energético, com a conivência de boa parte das autoridades. Esse conjunto de violações já está presente em diversas situações semelhantes, como foi apontado pela comissão que analisou as violações dos direitos humanos junto aos atingidos por barragens. Corrobora com esse entendimento o conteúdo indicado no relatório do Conselho de Defesa dos Direitos da Pessoa Humana (CDDPH):

É fundamental também que os causadores das violações reconheçam que a construção de barragens gera conflitos, "há que considerar que conflito, interlocução e negociação são partes essenciais e complementares de processos democráticos e participativos'. Portanto, os setores que tentam negar isso são, de certa forma, coniventes com a violação dos direitos humanos. (BRASIL, 2010a, p. 14, grifo no original).

Observando as questões preliminares, trazidas pelos documentos produzidos pelos atingidos bem como dos eventos realizados no município de Vargem e São José do Cerrito, com ampla participação dos atingidos, está demonstrado que ocorrem violações de direitos humanos - reproduzindo a situação de outras unidades - com um abandono das questões acerca da dignidade humana e aos direitos à cultura, à tradição e ao contato com a terra, não apenas em uma relação econômica, mas como fonte de vida e de sobrevivência. Em seguida, algumas considerações sobre os direitos envolvidos na questão.

\section{Do direito dos atingidos}

Considerando apenas a legislação pátria, é um tanto difícil caracterizar de forma contundente as violações de 
direitos dos atingidos por barragens, pois até o momento o Brasil não construiu uma legislação adequada que permita a configuração do conceito de atingido, com os direitos a ele inerentes. Mesmo assim, é indispensável um olhar para a Constituição Federal, como o art. $5^{\circ}$, no qual há menções que em uma compreensão extensiva poderia ser considerada, quando da análise de violação de direitos: "Art. $5^{\circ}$. [...],X - são invioláveis a intimidade, a vida privada, a honra e a imagem das pessoas, assegurado o direito à indenização pelo dano material ou moral decorrente de sua violação" (BRASIL, 1988).

Analisando a situação fática, é de fácil constatação que vários requisitos de respeito aos direitos dos atingidos foram descumpridos - como o da ampla participação da comunidade atingida na discussão e aprovação do projeto inicial. Além disso, a metodologia utilizada para a realização de estudos prévios - para a construção de barragens - caracteriza, sem dúvida alguma, uma "invasão" à propriedade dos atingidos, que nem ao menos sabem exatamente do que se trata. Essa situação caracteriza uma imposição aos atingidos, que sofrem com a falta de informação e com as incertezas acerca do seu próprio futuro e das suas famílias.

Ainda na análise constitucional, percebe-se que, ao menos para os proprietários, há alguns indicativos que caracterizam o dever de indenizar, como consta no art. $5^{\circ}$, inciso XXIV: “[...] a lei estabelecerá o procedimento para desapropriação por necessidade ou utilidade pública, ou por interesse social, mediante justa e prévia indenização em dinheiro, ressalvados os casos previstos nesta Constituição" (BRASIL, 1988). Evidentemente, o presente inciso não caracteriza exatamente a situação dos atingidos. No entanto, aproveita-se a ideia da prévia indenização. Também há um residual desse enquadramento, aquele dos que não se encaixam na condição de proprietários, mas atuam na agricultura e dependem da terra ocupada para garantir o seu sustento.

A respeito dos recursos hídricos, há apenas uma passagem determinando o estabelecimento de critérios para outorga; contudo, totalmente silente acerca dos aspectos sociais, 
econômicos e culturais decorrentes, como o inciso XIX, do art. 21: "Compete à União: [...] XIX - instituir sistema nacional de gerenciamento de recursos hídricos e definir critérios de outorga de direitos de seu uso" (BRASIL, 1988).

É no campo dos Direitos Humanos que há maior respaldo constitucional, mas apenas ao tratar do julgamento de questões humanitárias a Carta Magna estabelece a competência exclusiva da Justiça Federal, como se verifica:

Art. 109. Aos juízes federais compete processar e julgar:

$\mathrm{V}-\mathrm{A}$ as causas relativas a direitos humanos a que se refere o $\S 5^{\circ}$ deste artigo; (Incluído pela Emenda Constitucional $\mathrm{n}^{\circ} 45$, de 2004)

$\S 5^{\circ}$ Nas hipóteses de grave violação de direitos humanos, o Procurador-Geral da República, com a finalidade de assegurar o cumprimento de obrigações decorrentes de tratados internacionais de direitos humanos dos quais o Brasil seja parte, poderá suscitar, perante o Superior Tribunal de Justiça, em qualquer fase do inquérito ou processo, incidente de deslocamento de competência para a Justiça Federal. (BRASIL, 1988).

É evidente que a dimensão de gravidade - no presente caso - fica no abstrato; afinal, por se tratar de violação de direitos humanos, pode ser que para a pessoa que sofre a violação seja da maior gravidade, mas no olhar do observador ou mesmo do operador do direito não tenha a mesma dimensão.

Portanto, da Constituição Federal, resta uma tentativa de trazer a questão para os aspectos culturais, importantes para os direitos humanos, mas pouco reconhecidos e valorados no sistema capitalista, sobre a questão o preceito constitucional:

Art. 216-A. O Sistema Nacional de Cultura, organizado em regime de colaboração, de forma descentralizada e participativa, institui um processo de gestão e promoção conjunta de políticas públicas de cultura, democráticas e permanentes, pactuadas entre os entes da Federação e a sociedade, tendo por objetivo promover o desenvolvimento humano, 
social e econômico com pleno exercício dos direitos culturais. (BRASIL, 1988).

Diante desse quadro, um melhor dimensionamento da situação carece de um criterioso olhar sobre os tratados internacionais sobre o tema, dos quais o Brasil é signatário, como prescreve a Constituição Federal, no seu art. $5^{\circ}$ : “\$ $3^{\circ}$ Os tratados e convenções internacionais sobre direitos humanos que forem aprovados, em cada Casa do Congresso Nacional, em dois turnos, por três quintos dos votos dos respectivos membros, serão equivalentes às emendas constitucionais" (BRASIL, 1988).

Observa-se que a legislação pátria tem pouco a oferecer na defesa dos direitos dos atingidos. No entanto, o Brasil é signatário de diversos acordos e convenções internacionais, os quais - em tese - podem oferecer suporte aos operadores do direito, para encampar a defesa dos direitos dos atingidos, minimizando os complicados efeitos de uma brusca retirada do seu ambiente natural, da interrupção das relações familiares, sociais e culturais:

Assim, destacando os principais instrumentos internacionais vigentes no Brasil ingressaram no ordenamento jurídico nacional: em 1992, o Pacto de Direitos Civis e Políticos (1966), o Pacto dos Direitos Econômicos Sociais e Culturais - PIDESC (1966), a Convenção Americana sobre Direitos Humanos Pacto de San José da Costa Rica (1969); em 1998, a Convenção sobre Diversidade Biológica (1992); em 1999, o Protocolo Adicional à Convenção Americana sobre Direitos Humanos em Matéria de Direitos Econômicos Sociais e Culturais - Protocolo de San Salvador (1988); em 2004, a Convenção 169 da Organização Internacional do Trabalho sobre Povos Indígenas e Tribais (1989); em 2006, a Convenção para a Salvaguarda do Patrimônio Cultural Imaterial (2003); e em 2007, a Convenção sobre a Proteção e a Promoção da Diversidade das Expressões Culturais (2005). (BRASIL, 2010a, p. 20).

Aqui não está presente a intenção do convencimento jurídico, mas de apontar possibilidades de contemplar ou 
não determinadas situações, haja vista a dualidade - quase natural do sistema Judiciário - que se reflete nos julgamentos, pois nem sempre uma decisão representa o amplo espectro da "verdadeira justiça". Porém, é um compromisso de todas as instituições e ativistas que atuam na defesa dos direitos humanos o ato de promover reflexões acerca de possibilidades de avanços nas interpretações do marco regulatório que envolve o tema, invocando, evidentemente, o mais amplo rol de possibilidades, em favor da parte fragilizada na relação jurídica. A seguir, algumas ponderações sobre aspectos circundantes à legislação brasileira relacionadas com a condição do atingido por barragem e as violações a que está exposto, por ocasião da construção de uma usina hidrelétrica, como a São Roque.

Um dos instrumentos sobre os quais se lança um olhar é o Pacto Internacional sobre Direitos Econômicos, Sociais e Culturais, o qual foi recepcionado na legislação pátria pelo Decreto $\mathrm{n}^{\circ}$ 591, de 6 de julho de 1992, da Presidência da República, que assim determina: "Art.1‥O Pacto Internacional sobre Direitos Econômicos, Sociais e Culturais, apenso por cópia ao presente decreto, será executado e cumprido tão inteiramente como nele se contém" (BRASIL, 1992).

Alguns elementos do referido Pacto são indispensáveis, para uma análise criteriosa da situação dos atingidos por barragens, observa-se no seu preâmbulo:

Reconhecendo que, em conformidade com a Declaração dos Direitos do Homem, o ideal do ser humano livre, liberto do medo e da miséria não pode ser realizado a menos que sejam criadas condições que permitam a cada um desfrutar dos seus direitos econômicos, sociais e culturais, bem como dos seus direitos civis e políticos. (BRASIL, 1992).

No caso em apreço, está se falando de uma comunidade com características próprias, a qual sobrevive de forma autônoma, sem a necessidade de grandes esforços do Poder Público para se manter, pois as pessoas retiram da terra o seu sustento e nela constroem suas relações sociais, políticas, econômicas e culturais. 
Essa caracterização já encontra reconhecimento em inúmeros estudos realizados não somente no Brasil, mas no mundo, designando uma comunidade com essa caracterização como "comunidade tradicional" ou em outras situações como "comunidade ribeirinha". Isso decorre exatamente da identificação de modos de vida e de produção diferenciado, com respeito aos aspectos ambientais e valorização da biodiversidade da flora e da fauna. Portanto, do ponto de vista humanitário, observa-se no Pacto internacional da proteção cultural:

Art. $1^{\circ}[\ldots]$

3. Os Estados Partes do presente Pacto, incluindo aqueles que têm responsabilidade pela administração dos territórios não autônomos e territórios sob sua tutela, devem promover a realização do direito dos povos a disporem deles mesmos e respeitar esse direito, em conformidade com as disposições da Carta das Nações Unidas. (BRASIL, 1992).

Outro olhar indispensável, na mesma direção, é o relacionado com o trabalho das pessoas, onde $60 \%$ da população atingida têm uma única opção de trabalho: a agricultura. Com esse indicativo, há de se ter cautela em qualquer intervenção, por menor que seja - o que não é caso presente, pois está se desestruturando completamente a comunidade -, para que não ocorra uma degradação social, aumentando as desigualdades já gritantes na região e ampliando os custos sociais para todos os contribuintes, por meio de compensações sociais, enquanto o capital lucra com a situação. Nesse sentido, o Pacto citado merece atenção por parte dos operadores do direito:

Art. $6^{\circ}[\ldots]$

1. Os Estados Partes no presente Pacto reconhecem o direito ao trabalho que compreende o direito que têm todas as pessoas de assegurar a possibilidade de ganhar a sua vida por meio de um trabalho livremente escolhido ou aceito e tomarão medidas apropriadas para salvaguardar esse direito. (BRASIL, 1992).

É importante reafirmar que os direitos humanos vão além dos direitos civis, que os direitos humanos precisam 
estar além da legislação e provocar reflexões para além dos julgados e da jurisprudência, porque somente dessa forma será possível um viés de preservação do humano na sua relação com o capital, evitando a capitulação completa dos interesses humanitários.

Nessa relação internacional de proteção humanitária, o Brasil também recepciona o Protocolo Adicional à Convenção Americana sobre Direitos Humanos em Matéria de Direitos Econômicos, Sociais e Culturais, "Protocolo de São Salvador”. Isso ocorre através de Decreto Presidencial, com o seguinte teor:

Art. 10. O Protocolo Adicional à Convenção Americana sobre Direitos Humanos em Matéria de Direitos Econômicos, Sociais e Culturais, 'Protocolo de São Salvador', concluído em 17 de novembro de 1988, em São Salvador, El Salvador, apenso por cópia a este Decreto, deverá ser executado e cumprido tão inteiramente como nele se contém. (BRASIL, 1999).

Quanto ao Protocolo em questão, já no seu preâmbulo, trata do comprometimento de os Estados Partes cumprirem suas determinações, pois os aspectos são não apenas econômicos mas também culturais e sociais:

Levando em conta que, embora os direitos econômicos, sociais e culturais fundamentais tenham sido reconhecidos em instrumentos internacionais anteriores, tanto de âmbito universal como regional, é muito importante que esses direitos sejam reafirmados, desenvolvidos, aperfeiçoados e protegidos, a fim de consolidar na América, com base no respeito pleno dos direitos da pessoa, o regime democrático representativo de governo, bem como o direito de seus povos ao desenvolvimento, à livre determinação e a dispor livremente de suas riquezas e recursos naturais. (BRASIL, 1999).

O apelo para que medidas necessárias nesse sentido sejam tomadas já aparece, no seu art. $1^{\circ}$, que é contundente ao determinar a "Obrigação de adotar medidas"; portanto, 
não se trata de mera sugestão, mas de um comprometimento. E, como o Brasil recepcionou o presente Protocolo, este tem valor equivalente aos preceitos constitucionais. Logo, deve ser cumprido:

Os Estados Partes neste Protocolo Adicional à Convenção Americana sobre Direitos Humanos comprometem-se a adotar as medidas necessárias, tanto de ordem interna como por meio da cooperação entre os Estados, especialmente econômica e técnica, até o máximo dos recursos disponíveis e levando em conta seu grau de desenvolvimento, a fim de conseguir, progressivamente e de acordo com a legislação interna, a plena efetividade dos direitos reconhecidos neste Protocolo. (BRASIL, 1999).

Essa responsabilidade não é apenas do Estado enquanto Executivo normalmente omisso -, mas também do Legislativo e do Judiciário, além da significativa e indispensável contribuição do Ministério Público, seja federal, seja estadual. Então, as violações presentes na construção da UHE São Roque não podem passar despercebidas, pois os atingidos são a parte fragilizada na relação e merecem atenção redobrada sobre a sua condição de vulnerabilidade social, econômica e cultural. Nesse sentido, há antecedentes importantes, os quais precisam ser considerados:

Nas últimas duas décadas, as entidades de assessoria às comunidades atingidas por barragens em Minas Gerais e outras regiões do Brasil, e o Movimento dos Atingidos por Barragens, têm feito denúncias de diversas violações de direitos humanos e pressionada para reparação de danos sociais e ambientais e prevenção de violações no futuro. (ROTHMAN, 2010, p. 2).

O autor aponta, ainda, outras violações de direitos em empreendimentos energéticos no Brasil. Isso porque parte significativa dos atingidos, de acordo com o relatório final da Comissão, os estudos de caso Emboque e Fumaça realizados demonstram que muitas violações foram identificadas e as 
respectivas denúncias foram apresentadas pelos órgãos que defendem os atingidos, como o já mencionado $\mathrm{MAB}$ e a Comissão Pastoral da Terra (CPT/MG):

A denúncia sobre Emboque submetido à Comissão levantava as seguintes questões: a) direito à moradia adequada (segurança da posse, oferta de serviços, materiais e equipamentos urbanos, localização e habitabilidade e acessibilidade); b) violação dos direitos conexos ao direito à moradia adequada (danos ao meio ambiente e à saúde da população; afronta ao princípio maior de proteção da dignidade da pessoa humana, comprometimento do trabalho e dos meios de subsistência das famílias; violação do primado do trabalho com direito social fundamental; comprometimento do princípio de participação popular). (ROTHMAN, 2010, p. 4).

Diante das constatações apontadas, algumas sugestões foram apresentadas, no sentido de minimizar os impactos sobre os direitos humanos, relacionados com a construção de barragens no Brasil, as quais servem ao caso sob análise, entre eles:

- Imediata suspensão de situações, processos e ações, de responsabilidade direta ou indireta de agentes públicos ou privados, que configurem violação de direitos humanos.

- Reparação e compensação de violações de direitos humanos constatadas, de modo a resgatar, ainda que progressivamente, a dívida social e ambiental acumulada ao longo das últimas décadas.

- Prevenção de novas violações no futuro, através de políticas, programas e instrumentos legais que assegurem o pleno gozo dos direitos por parte das populações, grupos sociais, comunidades, famílias e indivíduos atingidos por barragens. (ROTHMAN, 2010, p. 6-7).

No entanto, até o momento nada foi feito na direção de cumprir as recomendações apresentadas pela Comissão. $\mathrm{O}$ motivo está na postura adotada pelas autoridades brasileiras, responsáveis pelas concessões de exploração de energia elétrica, 
que têm interesse na geração. E os empreendedores também estão muito interessados nas concessões, tendo em vista os fartos lucros decorrentes dessa matriz produtora de energia no País, com custos reduzidos. Portanto, não interessa a ambas as partes "criar empecilhos" aos empreendimentos, pois há interesses convergentes, ficam de fora apenas os atingidos.

Para fazer frente a essa dificuldade, uma alternativa é a definição do conceito de atingido. Nesse sentido, houve sinalização em determinar esse conceito, pelo Governo Federal, ao editar o Decreto no 7.342, da Presidência da República, de 26 de outubro de 2010, o qual institui o cadastro socioeconômico para identificação, qualificação e registro público da população atingida por empreendimentos de geração de energia hidrelétrica. Além disso, esse Decreto cria o Comitê Interministerial de Cadastramento Socioeconômico, no âmbito do Ministério de Minas e Energia. Porém, o Decreto $\mathrm{n}^{\circ}$ 7.342, não atende às expectativas dos atingidos, visto que

[...] busca definir um conceito de atingido, mesmo que insuficiente, e determina que se faça o cadastramento dos mesmos a partir deste conceito. A instituição do cadastro é uma reivindicação antiga do MAB e uma das recomendações da Comissão Especial. No entanto, há um risco deste Decreto se tornar inútil pela ação de alguns setores do governo, comprometidos com as grandes empresas da energia. O Decreto ainda não foi regulamentado e já há risco de desqualificar o documento que o então presidente Lula assinou. (BRASIL, 2010a, p. 18).

Diante dos comparativos, analisando a situação dos atingidos pela construção da UHE São Roque, é possível afirmar que as violações estão presentes na obra, na mesma proporção das observadas nas demais. Da mesma forma, na compreensão do MAB, aqui também está consolidada a dívida histórica com os atingidos. Isso de forma semelhante ao que consta na síntese do Relatório Final da Comissão Especial (BRASIL, 2010a, p. 23): "Por fim, reafirmamos que existe 
uma dívida social histórica das empresas donas de barragens, dos governos e do Estado brasileiro com populações atingidas por barragens. Esta dívida ainda não foi paga e aumenta em cada construção de novas barragens".

Em se tratando de violações de direitos humanos, é indispensável a compreensão de que elas não acontecem de forma estanque, mas possuem antecedentes históricos e atores atuais, que operam no sentido de efetivá-las. Por todo o conjunto analisado, constata-se que até existem dispositivos no ordenamento jurídico brasileiro capaz de oferecer algumas proteções aos atingidos. No entanto, ocorre outra interferência, a desigualdade de condições de acesso à justiça - especialmente pela falta de recursos financeiros -, os quais, por sua vez, limitam normalmente a capacidade técnica das intervenções:

De um lado, é possível afirmar que, em linhas gerais, a estrutura legal e normativa brasileira contém dispositivos vários para a proteção aos direitos humanos das populações e dos indivíduos atingidos pela implantação de barragens no território nacional. De outro lado, porém, é possível identificar limitações, omissões ou insuficiências no sistema normativo existente, o que, na prática, tem impedido ou dificultado o pleno exercício dos direitos acima referidos. Tradicionalmente, nosso sistema normativo tem canalizado para a via judicial a maioria dos conflitos, em detrimento de mecanismos alternativos, que poderiam favorecer a solução dos problemas diretamente pelas partes envolvidas - que, para uma justa e satisfatória negociação, precisariam evidentemente estar em condições de igualdade. (BRASIL, 2010a, p. 22).

Além disso, de acordo com a Comissão, um dos principais problemas é o da participação popular nas decisões sobre a construção ou não de usinas hidrelétricas. Esse é um ponto fundamental, pois se a população tem pleno domínio dos impactos que a construção vai provocar - seja ambiental, social, político, cultural ou econômico -, certamente, tomará decisão 
contrária à construção. Portanto, nisso está a importância da efetiva e plena participação da comunidade atingida, pois sem a construção não haverá o processo de violação de direitos, como o verificado:

Embora a Constituição Federal e os tratados internacionais ratificados pelo Brasil garantam o direito à informação e o direito de participação, o efetivo exercício desses direitos, no âmbito dos processos de implantação de barragens, carece de mais completa regulamentação, de modo a assegurar o acesso à informação suficiente, adequada e confiável, no momento e local apropriados, de maneira a permitir a participação informada de todos os interessados. (BRASIL, 2010a, p. 22).

Como já mencionado, se o Executivo e o Legislativo mostram-se limitados para assegurar os elementos necessários - para não afirmar omissos - ainda haveria a possibilidade do meio judicial. No entanto, como já mencionado, nesse campo também o atingido está em desvantagem, uma vez que ele é a parte frágil da relação processual e, muitas vezes, o Ministério Público, que deveria garantir o equilíbrio dessa relação, atua contrariamente à defesa dos direitos humanos, reforçando o papel exploratório do capital, representado pelo empreendedor, ressalvadas intervenções sensatas e importantes, ainda que isoladas, de Procuradores e Promotores:

Nem mesmo o Judiciário, a quem caberia, em última instância, garantir o respeito à legislação e preservar os direitos humanos, tem operado de maneira eficaz. O recurso ao Judiciário para fazer valer estes direitos, ao contrário e paradoxalmente, quase sempre termina em frustração. Enquanto empresas engajadas na construção e operação de barragens podem contar com advogados bem pagos, enquanto o Estado pode mobilizar estruturas jurídicas próprias e goza de tratamento judicial privilegiado, os atingidos raramente conseguem apoio ou assessoria jurídica adequada. Como se isso não bastasse, defrontam-se com o costumeiro distanciamento de juízes e tribunais das situações concretas da realidade social. A rapidez 
na cassação de liminares favoráveis a atingidos e na concessão de interditos proibitórios em favor das empresas tem como contra-face [sic] a lentidão e os artifícios protelatórios quando são questionadas ações das empresas - de que são prova reiterada os processos em que se questionam valores de indenizações, para citar um exemplo. (BRASIL, 2010a, p. 23).

Por fim, a Comissão - após levantamentos, análises de documentos, legislação das visitações in loco nas obras identificou um número relativo de questões e problemas que precisam ser aprofundados por essa ou outras comissões semelhantes. Assim, destacam-se 16 direitos sistematicamente violados, os quais devem ser de conhecimento público:

1. Direito à informação e à participação.

2. Direito à liberdade de reunião, associação e expressão.

3. Direito ao trabalho e a um padrão digno de vida.

4. Direito à moradia adequada.

5. Direito à educação.

6. Direito a um ambiente saudável e à saúde.

7. Direito à melhoria contínua das condições de vida.

8. Direito à plena reparação das perdas.

9. Direito à justa negociação, a tratamento isonômico, conforme critérios transparentes e coletivamente acordados.

10. Direito de ir e vir.

11. Direito às práticas e aos modos de vida tradicionais, assim como ao acesso e preservação de bens culturais, materiais e imateriais.

12. Direito dos povos indígenas, quilombolas e tradicionais.

13. Direito de grupos vulneráveis à proteção especial. 14. Direito de acesso à justiça e à razoável duração do processo judicial.

15. Direito à reparação por perdas passadas.

16. Direito de proteção à família e aos laços de solidariedade social ou comunitária. (BRASIL, 2010a, p. 16).

A dimensão dos direitos negados e a complexidade que os envolve, tendo em vista que muitas vezes as pessoas atingidas sequer têm a dimensão mínima do processo que 
está em andamento, quando da construção de barragens, é um fator que depõe contra os atingidos, porque estes desconhecem os seus direitos e, por isso, carecem de proteção humanitária para que sofram menos os impactos da construção de usinas hidrelétricas no Brasil, como é caso da usina São Roque.

\section{Considerações finais}

A situação dos atingidos pela UHE São Roque - pelos comparativos possíveis - é talvez ainda mais grave do que as demais unidades, especialmente no quesito de garantia de direitos de não proprietários. Embora a análise seja feita a partir das visualizações possíveis e das contribuições dos próprios atingidos, em atividades coletivas, documentos ou informações individuais, isso não diminui a importância na identificação dos direitos humanos violados.

As reflexões do presente estudo demonstram o quanto há de semelhanças entre as diversas usinas hidrelétricas construídas no Brasil, especialmente as relacionadas com: a negativa de reconhecimento de detentores de direito; a baixa valorização das terras e benfeitorias; a falta de incentivo aos reassentamentos coletivos; o completo descaso com as questões culturais e bens imateriais; entre outros fatores. Porém, também está presente a falta de participação, uma vez que o processo que deveria democratizar a discussão - por meio de audiência pública - realizada de forma quase invisível, sem a participação dos atingidos.

De acordo com as análises, na legislação há poucas possibilidades de garantia ampla dos direitos negados, considerando-se a ausência de um conceito de atingido e a falta de regulamentação acerca da garantia dos direitos que são afetados na remoção forçada. Por outro lado, demonstra-se que o Brasil é signatário de tratados e acordos internacionais, os quais deveriam ser observados administrativa e juridicamente, nas decisões pertinentes. No entanto, isso não ocorre na prática, seja pela falta de conhecimento dos atingidos, seja pela dificuldade em consultorias capazes de patrocinar discussões com essa complexidade. 
Diante da situação relatada pelos atingidos, das visitas in loco, da participação nas mobilizações e na análise documental e bibliográfica e das contribuições dos diversos depoimentos dos presentes em reuniões, acredita-se que será necessário conciliar um conjunto de alternativas, para que seja possível minimizar os impactos da construção dessa unidade na violação dos direitos humanos e na preservação ambiental. Então, será preciso fazer a luta no sentido de que os órgãos ambientais não concedam as licenças para o início do enchimento do lago e da entrada em operação da Usina, sem estarem totalmente resolvidos os aspectos sociais e humanitários pendentes, tendo em vista que o ser humano é parte integrante desse ambiente e, no caso, é afetado - como ser vivo, inclusive -, podendo verse privado do seu meio de subsistência.

Também é importante exigir do investidor que as negociações sejam de caráter coletivo, ressalvando-se apenas as exceções de atingidos que tenham interesses divergentes. Ainda é preciso o apoio institucional da parte do Judiciário e do Ministério Público e de instituições dos direitos humanos comprometidos com a causa, para que continuem intercedendo, exigindo a garantia de direitos e fiscalizando o respeito aos atingidos. Outra questão fundamental para minimizar as violações sofridas é que os atingidos permaneçam na sua atividade habitual, ou seja, a agricultura; para isso, a principal forma de compensação dos atingidos deve ser a do reassentamento coletivo, garantindo as mesmas ou melhores condições do que as atualmente existentes.

No entanto, em tudo isso é preciso exigir a inclusão dos filhos de proprietários, não proprietários, pequenos meeiros, parceiros, posseiros - que retiram seu sustento da terra atingida - como detentores de direitos equivalentes ao de proprietário para efeito de acesso à terra.

Nos casos de demandas judiciais, é importante que sejam considerados, além do ordenamento jurídico pátrio, os tratados e convenções internacionais, que tratam do assunto, ampliando no que for possível para garantir a dignidade da pessoa humana e o respeito ao patrimônio, material e imaterial 
da comunidade atingida. Portanto, uma ação conjunta desses órgãos pode minimizar os impactos da construção da UHE São Roque, na violação dos direitos humanos dos atingidos pela obra e seu funcionamento.

\section{Referências}

ASSOCIAÇÃO COORDENAÇÃO NACIONAL DOS ATINGIDOS POR BARRAGENS (Org.). As lutas dos atingidos por barragens por direitos humanos. São Paulo, 2013. Disponível em: <http://www.mabnacional.org.br/publicacao/cartilha-lutasdos-atingidos-por-barragens-por-direitos-humanos>. Acesso em: 10 jul. 2016.

BRASIL. Constituição (1988). Constituição da República Federativa do Brasil de 1988. Disponível em: <http://www.planalto. gov.br/ccivil_03/constituicao/constituicaocompilado.htm>. Acesso em: 20 mai. 2015.

. Decreto no 591, da Presidência da República, de 6 de julho de 1992. Atos Internacionais. Pacto Internacional sobre Direitos Econômicos, Sociais e Culturais. Promulgação. Diário Oficial da República Federativa do Brasil, Brasília, DF, 7 jul. 1992. Disponível em: <http://www.planalto.gov.br/ccivil_03/decreto/1990-1994/ d0591.htm>. Acesso em: 20 mai. 2015.

. Decreto no 3.321, de 30 de dezembro de 1999. Promulga o Protocolo Adicional à Convenção Americana sobre Direitos Humanos em Matéria de Direitos Econômicos, Sociais e Culturais "Protocolo de São Salvador", concluído em 17 de novembro de 1988, em São Salvador, El Salvador. Diário Oficial da República Federativa do Brasil, Brasília, DF, 31 dez. 1999. Disponível em: <http://www.planalto.gov.br/ccivil_03/decreto/d3321.htm>. Acesso em: 20 mai. 2015.

- Ministério de Minas e energia. Conselho de Defesa dos Direitos da Pessoa Humana. Relatório final Comissão Especial de "atingidos por barragens", regulamentado pelas Resoluções $\mathbf{n}^{\text {os }}$ 26/06, 31/06, 01/07, 02/07, 05/07. Brasília, 2010a. Disponível em: <file:///C:/Users/curso01/Downloads/CDDPH_Relatorio_final. pdf $>$. Acesso em: 5 jul. 2016.

. Decreto $\mathrm{n}^{\circ} 7.342$, da Presidência da República, de 26 de outubro de 2010. Institui o cadastro socioeconômico para identificação, qualificação e registro público da população atingida por empreendimentos de geração de energia hidrelétrica, cria o 
Comitê Interministerial de Cadastramento Socioeconômico, no âmbito do Ministério de Minas e Energia, e dá outras providências. Diário Oficial da República Federativa do Brasil, Brasília, DF, 26 out. 2010b. Disponível em: <http://www.planalto.gov.br/ccivil_03/ decreto/d3321.htm>. Acesso em: 20 mai. 2015.

- Ministério de Minas e Energia.UHE São Roque. Contrato de concessão $\mathbf{n}^{\circ}$ 01/2012. Brasília, 20 ago. 2012.

MINISTÉRIO PÚBLICO FEDERAL. Procuradoria da República em Santa Catarina - Subseção Judiciária de Joaçaba. Inquérito Civil Público. Autos IC no 1.33.004.000109/2010-91. Relatório de reunião realizada em 1\%/07/2014 - Ministério Público Federal - MPF - Procuradoria da República em Santa Catarina subseção judiciária de Joaçaba. Joaçaba, 2010.

RAFFESTIN, Claude. Por uma geografia do poder. Tradução de Maria Cecília França. São Paulo: Ática, 1993.

ROTHMAN, Franklin Daniel. Violação dos direitos humanos em barragens: o relatório final da comissão especial e os casos de Emboque e Fumaça. Brasília, 22 nov. 2010. Disponível em: <http:// conflitosambientaismg.lcc.ufmg.br/wp-content/uploads/2014/04/ TAMC-ROTHMAN_Franklin_-_Violacao_dos_direitos_ humanos_em_barragens.pdf>. Acesso em: 7 jul. 2016.

SAQUET, Marcos Aurelio. Abordagens e concepções sobre território. 4. ed. São Paulo: Outras Expressões, 2015.

Submetido em: 20/07/2017

Aceito em: 30/07/2017 


\title{
CONSTRUCTION OFTHE HYDROELECTRIC SÃO ROQUE
}

\begin{abstract}
The present study deals with the violation of human rights in the construction of the São Roque Hydroelectric (UHE), under construction on the Canoas river, between the municipalities of Vargem and São José do Cerrito in Santa Catarina. The empirical basis stems from individual dialogues, meetings, mobilizations and documents produced by those affected. The theoretical basis is supported by several documents of human rights commissions that analyzed human rights violations in other works, in addition to the international treaties and agreements to which Brazil is a signatory and incorporated them into its legislation. It also demonstrates the main rights denied to those affected and how the violation of human rights in this case materializes. A discussion is still held about the role of the Movement of the Affected by Dams (MAB) in the fight to defend the rights of those affected and their legitimacy of representation. It also proposes a suggestion of concept of reached and the necessary mechanisms for the guarantee of their rights. Finally, it indicates a collection of procedures that should be taken in order to stop human rights violations in the completion of the work and its operation.
\end{abstract}

Keywords: Human Rights. Loc Movement. Energy Sector. Dam. 